\title{
Comparative Studies for What?
}

\author{
Pedro Guedes de Carvalho*
}

EDITORIAL

ISCPES stands for International Society for Comparative Physical Education and Sports and it is going to celebrate its $40^{\text {th }}$ anniversary in 2018. Since the beginning (Israel 1978) the main goals of the Society were established under a worldwide mind set considering five continents and no discrimination of any kind. The founders wanted to compare Physical Education and Sports across the world, searching for the best practices deserving consideration and applied on the purpose of improving citizen quality of life. The mission still stands for "Compare to learn and improve".

As all the organizations lasting for 39 years, ISCPES experienced several vicissitudes, usually correlated with world economic cycles, social and sports changes, which are in ISS journal articles International Sport Studies.

ISS journal is Scopus indexed, aiming to improve its quality (under evaluation) to reach more qualified students, experts, professionals and researchers; doing so it will raise its indexation, which we know it is nowadays a more difficult task. First, because there are more journals trying to compete on this academic fierce competitive market; secondly, because the basic requirements are getting more and more hard to gather in the publishing environment around Physical Education and Sports issues. However, we can promise this will be one of our main strategic goals.

Another goal I would like to address on this Editorial is the language issue. We have this second strategic goal, which is to reach most of languages spoken in different continents; besides the English language, we will reach Chinese, Spanish and Portuguese speaking countries. For that reason, we already defined that all the abstracts in English will be translated into Chinese, Spanish and Portuguese words so people can find them on any search browser. That will expand the demand for our journal and articles, increasing the number of potential readers.
Of course this opportunity, given by Motricidade, can be considered as a good example to multiply our scope.

In June 2017 we organized a joint Conference in Borovets, Bulgaria, with our colleagues from the BCES - Bulgarian Society for Comparative Educational Studies. During those days, there was an election to appoint a new (Portuguese) president. This constitutes an important step for the Portuguese speaker countries, which, for a $4^{\text {th }}$ year term, will have the opportunity to expand the influence of ISCPES Society diffusing the research results we have been achieving into a vast extended new public and inviting new research experts to innovative debates. This new president will be working with a wide geographical diverse team: the Vice President coming from a South American country (Venezuela), and the other several Executive Board members are coming from Brazil, China, Africa and North America. This constitutes a very favorable situation once, adding to this, we kept the previous editorial team from Australia and Europe. We are definitely committed to improve our influence through new incentives to organize several regional (continental) workshops, seminars and Conferences in the next future.

The international research is crossing troubled times with exponential number of new indexed journals trying to get new influence and visibility. In order to do that, readers face new challenges because several studies present contradictory conclusions and outcome comparisons still lacking robust methodologies. Uncovering these issues is the focus of our Society.

In the past, ISCPES started its activity collecting answers to the same questions asked to several experts in different countries and continents across the world. The starting studies developed some important insights on several issues concerning the way Physical Education professionals approached their challenges. In the very starting documents

\footnotetext{
${ }^{*}$ Corresponding author: Research Center in Sports Sciences, Health Sciences \& Human Development, CIDESD,
} Vila Real, Portugal. E-mail: pedro.guedes.carvalho@gmail.com 
ISCPES activity focused in identifying certain games and indigenous activities that were not understood by people in other parts of the world, improving this international understanding and communication. This first attempt considered six groups of countries roughly comprehending 26 countries from all the continents.

ISCPES has on its archives several seminal works, $\mathrm{PhD}$ proposals and program proposals, which constitutes the main theoretical framework considered in some textbooks printed at the end of the sixties in the $\mathrm{XX}^{\text {th }}$ century.

The methods used mostly sources' country comparisons, historic development of comparative education systems, list of factors affecting those systems and a systematic analysis of case studies; additionally, international organizations for sports and physical education were also required to identify basic problems and unique features considered for the implementation of each own system. At the time, Lynn C. Vendien \& John E. Nixon book "The World Today in Health, Physical Education and Recreation", Englewood Cliffs, New Jersey: Prentice-Hall, Inc. 1968, together with two monographies from William Johnson "Physical Education around the World", 1966, 1968, Indianapolis, Phi Epsilon Kappa editions, were the main textbook references.

The main landscapes of interest were to study sports compared or the sport role in Nationalisms, Political subsidization, Religion, Race and volunteering versus professionalism. The goal was to state the true place of sports in societies.

In March 1970, Ben W. Miller from the University of California compiled an interesting Exhibit n.1 about the main conclusions of a breakfast meeting occurred during the American Association for Health, Physical Education and Recreation. There, they identified thirty-one individuals, which had separate courses in "Comparative and/or International Physical Education, Recreation and Sports"; one month later, they collected eighteen responses with the bibliographic references they used. On this same Exhibit $\mathrm{n} .1$ there is detailed information on the title, catalogue description, date of initial course (1948, the first), credit units, eligibility, number of year offer, type of graduation (from major to doctorate and professional). Concluding, the end of the sixties can be the mark of a well-established body of literature in comparative education and sports studies published in several scientific journals.

What about the XXI ${ }^{\text {st }}$ century? Is it still important to compare sports and education throughout the world? Only with qualitative methods? Mixed methods?

We think so. That is why, after a certain decline and fuzzy goal definition in research motivations within ISCPES we decided to innovate and reorganize people from physical education and sports around this important theme of comparative studies. Important because we observe an increasing concern on the contradictions across different results in publications under the same subject. How can we infer? What about good research questions which get no statistically significant results? New times are coming, and we want to be on that frontline of this move as said by Elsevier "With RMR (results masked review) articles, you don't need to worry about what editors or reviewers might think about your results. As long as you have asked an important question and performed a rigorous study, your paper will be treated the same as any other. You do not need to have null results to submit an RMR article; there are many reasons why it can be helpful to have the results blinded at initial review".https://www.elsevier.com/connect/reviewer s-update/results-masked-review-peer-reviewwithout-publication-bias.

This is a very different and challenging time. Our future strategy will comprehend more cooperation between researchers, institutions and scientific societies as an instrument to leverage our understanding of physical activity and sports through different continents and countries and be useful for policy designs.

Next 2018, on the occasion of the UE initiative Sofia - European Capital of Sport 2018 we - Bulgarian Comparative Education Society (BCES) \& the International Society for Comparative Physical Education and Sport (ISCPES) - will jointly organize an International Conference on Sport Governance around the World.

Sports and Physical Education are facing complex problems worldwide, which need to be solved. For health reasons, a vast number of organizations are popularizing the belief that physical education and sports are 'a must' in order to promote human activity and movement. However, several studies 
show that modern lifestyles are the main cause for people's inactivity and sedentary lifestyles.

Extensive funded programs used to promote healthy lifestyles; sports media advertising several athletes, turning them into global heroes, influencers in a new emerging industry around sports organizations. Therefore, there is a rise in the number of unethical cases and corruption that influence the image of physical education and sports roles.

We, the people emotional and physically involved with sports and physical activity must be aware of this, studying, discussing and comparing global facts and events around the world.

This Conference aims to offer an incentive to colleagues from all continents to participate and present their latest results on four specific topics: 1 . Sport Governance Systems; 2. Ethics and Corruption in Physical Education and Sports Policies; 3. Physical Education and Sport Development; 4. Training Physical Educators and Coaches. Please consider your selves invited to attend. Details in http://bcesconvention.com/ 